High reliability organisations

\section{Keep the celebrations short}

\section{R L Wears}

\section{"Success without victory" in patient safety}

$\mathrm{P}$ atient safety seems irritatingly positive. Its scientific literature and conference proceedings are replete with tales of improvement and stories of success. This is partly understandable. It is difficult to move people and organisations to change when the outcome is uncertain; hospitals and funding organisations do not like to hear that projects in which they have invested have failed; "safety champions" - the individuals who are the driving forces for change-passionately want to succeed; publication is not eagerly sought when high hopes have been deflated; and editors may fear inducing a paralysing "learned helplessness" in readers. Like Cassandra in ancient Troy, the few lonely voices ${ }^{12}$ cautioning that the road to safer care might be long and hard, that the outcome is in doubt, and that "success" (however we define it) once achieved might be difficult to hold, have largely been marginalised, drowned out by the upbeat chorus. An observer from another planet reviewing safety conferences, newsletters, proceedings, and papers over the last 5-10 years might reasonably wonder why the field still exists since all the problems seem to be so easily solved. There is no sense of what Rochlin" calls "the continuing expectation of future surprise".

This rosy view of safety in health care contrasts sharply with other thinking on safety in complex sociotechnical systems. ${ }^{3-10}$ Here it is held that the level of safety in an organisation is the result of a constantly renegotiated set of inevitable tradeoffs; that the organisation is being tossed about in a "safety space", buffeted by the forces of economics, resource constraints, workload, external demands, technological change, and the perceived boundary of unsafe performance. Safety interventions can tip the negotiated balance in one direction but the forces still remain and, without active and sustained effort, even the interventions themselves can become subverted. Hirschhorn ${ }^{5}$ and Woods ${ }^{11}$ have expressed this cogently as The Law of Stretched Systems: "Every system operates always at its capacity. As soon as there is some improvement, some new technology, we stretch it." Thus, safety interventions typically become converted to production; since work is now safer, more work is expected in less time or with fewer resources or under more dangerous conditions, and so on. Striving for safety in this world is analogous to fighting a long guerilla war: there are no clearcut victories; there are occasional disturbing losses; the enemy is invisible, pervasive, avoids our strengths and attacks our weaknesses unexpectedly; and there is no end in sight. The most one can hope for is a sort of "success without victory" where success means reducing but not eliminating the threat. ${ }^{12}$

The paper by Roberts et al in this issue of $Q S H C^{13}$ provides a sobering and much needed contrast to the general cheeriness of safety papers in health care. Their case study of how highly safe performance in an organisation was gradually lost due to changes in leadership, personnel, and philosophy underscores the fragility and evanescence of safety in complex systems. It emphasises that, while safe performance can be difficult to attain, it can easily be lost, and that such losses can come as the result of good intentions.

Although there were many dimensions to the organisational changes that were temporally associated with the degradation in performance in this case study, two seem particularly relevantthe reversion to a more hierarchical "command and control" model of organisation and the replacement of contextually sensitive, loop based decision making methods-“"sensemaking through action"- by normative rationalised protocols. These two changes are ironic because they were intended to improve care and because they follow the standard medical model of organising; but they had the opposite effect. Worse, the organisation did not seem to be able to break out of this vicious cycle; one can imagine that the response to deteriorating performance might have been still tighter control and ever more detailed protocolisation.

Striving for "success without victory" in patient safety may seem cynical, or at least uninspiring, but it is realistic and avoids false hopes, inflated expectations, and unjustifiable disappointments. Paradoxically, the "high reliability organisations" that we in health care would like so much to emulate have got where they are by finding ways to sustain such an approach; to foster the continuing expectation of future (unpleasant) surprises; and to keep their celebrations short. Such unwelcome views have been punished in other domains ${ }^{12}$ but, more often, like Cassandra, they are just ignored. Keep the celebrations short.

Qual Saf Health Care 2005; 14:154.

doi: 10.1136/qshc.2005.013946

Correspondence to: $\operatorname{Dr} R$ L Wears, Professor, Clinical Safety Research Unit, 10th Floor, Queen Elizabeth the Queen Mother Building, St Mary's Hospital, London W2 1NY, UK; wears@ ufl.edu

\section{REFERENCES}

1 Alvarado C, Cao C, Klein G, et al. The role of human factors in health care-2020. In: Proceedings of the 48th Human Factors and Ergonomics Society. New Orleans, LA, 2004:1764-7.

2 Nemeth C, Cook RI, Patterson ES, et al. Afterwords: the quality of medical accident investigations and analyses. In: Proceedings of the 48th Human Factors and Ergonomics Society. New Orleans, LA, 2004:2084-8.

3 Rochlin GI. Safe operation as a social construct. Ergonomics 1999;42:1549-60.

4 Rasmussen J. Risk management in a dynamic society. Safety Sci 1997;27:183-213.

5 Hirschhorn L. Law of stretched systems (quoted in Woods and Cook). http://www.ctlab.org/ properties/pdf\%2Ofiles/

Characteristics\%20 of $\% 20$ Patient $\% 20$ Safety.pdf (accessed 2 February 2005)

6 Reason J. Managing the risks of organizational accidents. Aldershot, UK: Ashgate, 1997.

7 Woods DD, Cook RI. Tradeoffs/characteristics of patient safety: five principles that underlie productive work, http://www.ctlab.org/ properties/pdf\%2Ofiles/ Characteristics\%20of\%20Patient\%20Safety.pdf (accessed 2 February 2005)

8 Amalberti R. The paradoxes of almost totally safe transportation systems. Safety Sci 2002;37:109-26.

9 Grasha AF. Lesson in patient safety from 'A Beautiful Mind'. Nurs Econ 2002;20:284-6, 91

10 Cook RI, Rasmussen J. "Going solid": model of system dynamics and consequences for patient safety. Qual Saf Health Care 2005;14:130-4

11 Woods DD. Steering the reverberations of technology change on fields of practice: laws that govern cognitive work, http://csel.eng.ohiostate.edu/laws/laws_talk/media/0_steering.pdf (accessed 23 September 2002).

12 Fallows J. Success without victory. The Atlantic Monthly 2004:295:80-9.

13 Roberts K, Madsen P, Desai V, et al. A case of the birth and death of a high reliability healthcare organization. Qual Saf Health Care 2005;14:216-20. 
Treatment according to guidelines

\section{I just want the protocol, doctor! E McColl}

\section{It may not be easy for patients to insist on treatment as part of a guideline protocol}

S ome years ago I was diagnosed with chronic open angle glaucoma. Initial treatment involved laser therapy with a daily regimen of eye drops since then. At this year's review visit I was told that my intraocular pressure was once again raised and that other treatment options, including surgery and/or long term treatment with drugs with unpleasant side effects, might be required. As an informed consumer of health care and an advocate of evidence based medicine, I decided to search for guidelines and protocols on the management of my condition.

A search of the NICE website (www.nice.org.uk) found nothing of relevance. However, a visit to the National Guidelines Clearing House (www.guidelines.gov) soon led me to the American Optometric Association's clinical practice guideline on the care of the patient with open angle glaucoma. ${ }^{1} \mathrm{I}$ was slightly concerned to read in the opening pages of this document that "clinicians should not rely on this clinical guideline alone for patient care and management" but should instead refer to the cited references and sources for a more detailed treatment of the evidence. Could I be sure that my ophthalmologist and ophthalmic surgeon would have chased up this additional material? Did I personally need to access some or all of the almost 600 references in order to make an informed choice about my treatment? Indeed, was the guideline actually relevant to my current dilemma at all? Reading further, I found that it is addressed primarily to optometrists rather than to those providing therapeutic interventions, though the role of the optometrist in informing and educating patients about treatment options and the potential adverse effects of treatment options is addressed.
A further source of concern for me was the lack of a lay or consumer summary of this very comprehensive guideline. Although I have been involved in health services research for over 20 years, I am not clinically qualified. The specialist terminology and language used in this document render recourse to a medical dictionary. Furthermore, there is no evidence of consumer involvement in the development of this guideline, with the result that there is scant reflection of the patient's perspective and experience of the condition and its management. We are told that patient adherence to treatment regimens is frequently poor, often because of unpleasant side effects of topical and oral drugs, but the cited references are in many cases over 20 years old. ${ }^{2}$ The NICE guideline development process requires that viewpoints of patients and their carers be taken into account, and all NICE guideline development groups have consumer representatives. A recent report from NICE $^{3}$ highlighted the unique and essential nature of these representatives' contribution to the guideline development process.

Elsewhere in this issue, West and colleagues $^{4}$ report on the comparison of patients with pre-eclampsia who were enrolled in a clinical trial, and a control group of non-participants with the same condition who were nonetheless managed according to a strict treatment protocol. It has often been argued that patients opt to participate in trials in the hope that they will receive treatment options unavailable in routine practice, or will at least benefit from higher quality of care because of the rigorous study protocols applied to trial participants. ${ }^{5}$ However, West and colleagues it difficult for me to understand without found no differences in clinical outcomes and only minor differences with respect to the process of care between the two groups. They conclude that "in routine practice, patients may be well advised to insist on treatment as part of a protocol".

My own experience in trying to find a guideline appropriate to the management of my particular health problem suggests that this may not be as straightforward or as simple a process as these authors imply! Are appropriate guidelines always available and accessible? How well equipped are the majority of patients to find and appraise such guidelines? Will the patient perspective have been adequately captured in the guideline development process? Will clinicians be aware of the guidelines and will they be willing to accede to patient requests for protocol driven treatment? Undoubtedly, as West and colleagues conclude, and as the NICE initiative on protocol based care (http:// www.modern.nhs.uk/protocolbasedcare) indicates, guidelines have enormous potential to ensure the quality, safety and effectiveness of health care. Encouraging professionals and patients to realise that potential remains a challenge for all of us.

Qual Saf Health Care 2005;14:155. doi: 10.1136/qshc.2005.013953

Correspondence to: Elaine McColl, Director, Newcastle Clinical Trials Unit, School of Population and Health Sciences, University of Newcastle upon Tyne, Newcastle upon Tyne NE2 4AA, UK; e.mccoll@newcastle.ac.uk

\section{REFERENCES}

1 Lewis TL, Barnebey HS, Bartlett JD, et al. Optometric clinical practice guideline - care of the patient with open angle glaucoma: reference guide for clinicians, 2 nd ed. St Louis, MO: American Optometric Association, 2002.

2 Bloch S, Rosenthal AR, Friedman L, et al. Patient compliance in glaucoma. $\mathrm{Br} J$ Ophthalmol 1977;61:531-4

3 Jarrett $L$, the Patient Involvement Unit. A report on a study to evaluate patient/carer membership of the first NICE guideline development groups. London: National Institute for Clinical Excellence (NICE), 2004.

4 West J, Wright J, Tuffnell D, et al. Do clinical trials improve quality of care? A comparison of clinical processes and outcomes in patients in a clinical trial and similar patients outside a trial where both groups are managed according to a strict protocol. Qual Saf Health Care 2005; 14:175-8.

5 Braunholz DA, Edwards SL, Lilford R. Are randomised trials good for us? Evidence for a trial effect. J Clin Epidemiol 2001;54:217-24. 